\title{
Hydration status, sweating rate, heart rate and perceived exertion after running sessions in different relative humidity conditions: a randomized controlled trial
}

Matheus A. do Nascimento a,b,*, Flávio Ricardo Guilherme ${ }^{a}$, Sandra A. Ferreirac, Renata S.B. Januário ${ }^{\mathrm{b}, \mathrm{d}}$, Alex S. Ribeiro $^{\mathrm{b}, \mathrm{d}}$, Jerry L. Mayhew ${ }^{\mathrm{e}}$,Fabrício Voltarellif, Letícia T. Cyrino ${ }^{\mathrm{b}}$, Paulo Sugihara Junior ${ }^{\mathrm{b}}$, Danilo Rodrigues Pereira da Silvag, Marcos R. Queirogah ${ }^{\text {h }}$

Keywords:

Dehydration;

Aerobic exercise;

Physiological exertion;

Rating of perceived

exertion.

\section{Palavras Chave:}

Desidratação;

Exercícios aeróbicos;

Esforço fisiológico;

Esforço percebido.

\section{Palabras Clave:}

Deshidratación;

Ejercicio aeróbico;

Esfuerzo fisiológico;

Esfuerzo percibido.

\begin{abstract}
The purpose of this study was to analyze the impact of running in normal relative humidity $(\mathrm{RH}=53 \%)$ and very high $\mathrm{RH}(94 \%)$ on hydration status $(\mathrm{HS})$, sweating rate (SR), heart rate (HR), and rating of perceived exertion (RPE). Fourteen men ( $25.2 \pm 6.6 \mathrm{yrs}$ ) performed two sessions of treadmill running. Body mass (normal RH: $-1.35 \%$, very high $\mathrm{RH}:-1.65 \%$ ) HS (normal RH: $-14.8 \%$; very high $\mathrm{RH}:-20.8 \%$ ) were reduced while $\mathrm{RPE}$ (normal $\mathrm{RH}:+26 \%$; very high $\mathrm{RH}:+28 \%$ ) and HR were increased (very high RH: +5.8\%: 20-40 min, +3.1\%: 40-60 min, +3\%: 20-40 min; +2.3\%: 40-60 min for normal RH). As expected, SR was significantly greater during very high $\mathrm{RH}(-20 / 8 \%)$ compared to normal $\mathrm{RH}(-14.8 \%)$. Running in very high $\mathrm{RH}$ at moderate temperature has a greater negative impact on SR, HS, body mass, HR, RPE in men than running in normal $\mathrm{RH}$ at the same temperature, which places the runner in greater danger of heat illnesses such as heat exhaustion or heat stroke.
\end{abstract}

\section{RESUMO}

Analisar o impacto da corrida em diferentes humidade relativa (HR) (normal (53\%), muito alto (94\%)), estado de hidratação (EH), taxa de transpiração (TT), freqüência cardíaca (FC), esforço percebido (RPE). Quatorze homens (25,2 anos) realizaram duas sessões de corrida em esteira. Massa corporal (HR normal: $-1,35 \%$, HR muito alta: $-1,65 \%$ ) e EH reduziram (HR normal: $-14,8 \%$, HR muito alta: $-20,8 \%$ ), RPE (HR normal: + 26\%, HR muito alta: + 28\%), aumento da FC (HR muito alta: + 5.8\%: 20-40 min, + 3.1\%: 40-60 min, HR normal: + 3\%: 20-40 min; + 2.3\%: 40-60 min). TT foi significantemente diferente entre HR (HR normal: -14.8\%, HR muito alta: -20.8\%). Há um impacto negativo na corrida em EH, massa corporal, FC e RPE em homens com HR normal e muito alta, e TT é mais afetada com HR muito alta.

\section{RESUMEN}

El objetivo de este estudio fue analizar las repercusiones de correr con diferentes niveles de humedad relativa (HR) (normal [53\%], muy alta [94\%]) sobre el estado de hidratación (EH), la tasa de sudoración (TS), la frecuencia cardíaca (FC) y el esfuerzo percibido (EP). Catorce hombres $(25,2 \pm 6,6$ años) realizaron dos sesiones en cinta de correr. La masa corporal (HR normal: $-1,35 \%$; HR muy alta: $-1,65 \%$ ) y el EH (HR normal: $-14,8 \%$; HR muy alta: $-20,8 \%$ ) se redujeron, mientras que el EP (HR normal: $+26 \%$; HR muy alta: $+28 \%$ ) y la FC (HR muy alta: $+5,8 \%$ : 20-40 min; $+3,1 \%$ : $40-60$ min; HR normal: + 3\%: 20-40 min; + 2,3\%: 40-60) aumentaron. La TS fue considerablemente diferente entre las HR (HR normal: -14,8\%; muy alta HR: $-20,8 \%)$. Hay repercusiones negativas por correr con una HR muy alta y una temperatura moderada en TS, EH, masa corporal, FC y EP en corredores que corren a una HR normal a la misma temperatura, lo que sitúa a estos en gran peligro de sufrir un enfermedad provocada por el calor, como agotamiento por calor o golpe de calor.

\footnotetext{
a Universidade Estadual do Paraná (UNESPAR), Paranavaí Campus, Paranavaí, PR, Brazil. Exercício, Londrina, PR, Brazil.

c Universidade Estadual de Londrina, Programa de Educação Física, Londrina, PR, Brazil.

d Universidade Norte do Paraná, Centro de Pesquisa em Ciências da Saúde, Londrina, PR, Brazil.

e Exercise Science Program, Truman State University, Kirksville, MO, USA.

f Universidade Federal do Mato Grosso (UFMT), Cuiabá, MT, Brazil.

g Universidade Federal de Sergipe (UFS), São Cristóvão, SE, Brazil.

${ }^{\text {h }}$ Universidade Estadual do Centro-Oeste, UNICENTRO, CEDETEG Campus, Guarapuava, PR, Brazil.
}

b Universidade Estadual de Londrina, Centro de Educação Física e Desporto, Grupo de estudo e de pesquisa em Metabolismo,Nutrição e

\section{*Autor correspondente:}

Matheus A. do Nascimento

E-mail: matheusamarante@hotmail.com 


\section{INTRODUCTION}

Running training, as well as other physical exercise modalities, causes numerous acute physiological alterations, such as the impaired hydration status (HS). Inadequate hydration conditions before and during an exercise session can have serious negative effects on performance and physiological function (Shirreffs et al., 2005; Maughan et al., 2007). During exercise, negative alterations in HS are mainly caused by increased sweating rate (SR) which can be influenced by individual factors (e.g., age, sex, hydration and feeding condition), type of physical exercise performed, type of clothing used during exercise, and environmental conditions (Sawka et al., 2007).

Among the significant environmental factors that can cause thermal discomfort and alteration in HS and SR, environmental temperature and relative humidity $(\mathrm{RH})$ are considered the most important. These variables can drastically influence the body's thermoregulation since the more the environment temperature rises, the greater will be the SR. The higher the RH, the less will be the sweat evaporation, which will drive up the exerciser's heat production and SR consequently increase the rating of perceived exertion (RPE) (Millard-Stafford et al., 2007; Maughan et al., 2012). Heat production during exercise is approximately 15-20 times higher than during resting conditions. Central body temperature may increase $1{ }^{\circ} \mathrm{C}$ every five minutes of exertion if there is no thermoregulatory adjustment (e.g., sweat evaporation) (Nadel et al., 1977; Gleeson, 1998). Therefore, adequate maintenance of HS is important for thermoregulation to maintain adequate cardiovascular function and physical performance during exercise (Gleeson, 1998; Coris et al., 2004).

Studies that seek to verify the physiological and perceptive responses to running under different conditions of $\mathrm{RH}$ may convince athletes and recreational practitioners to adopt better hydration strategies prior to running on a day with high RH (Goulet et al., 2008; Morris et al., 2015). Although previous studies have evaluated physiological responses to both elevated RH and heat (Shirreffs et al., 2005; Maughan et al., 2007; Murray et al., 2007), more studies are needed to assess physiological responses in conditions of high $\mathrm{RH}$ without elevated temperature since the mechanisms that decrease HS in high heat and high RH are different. To our knowledge, there is no study that has attempted to verify the physiological effects of running in controlled environments with same temperature but different $\mathrm{RH}$.

Therefore, the aim of this study was to analyze the impact of a running session in two conditions of controlled temperature with different RH on HS, SR, HR, and RPE. Our hypothesis was that the running session in a very high $\mathrm{RH}$ condition could increase $\mathrm{SR}, \mathrm{HR}$, and $\mathrm{RPE}$, and decrease HS more than in normal RH session independent of environmental temperature.

\section{METHODS}

This investigation was approved by the local University Ethics Committee, according to Helsinki Declaration, the norms of Resolution 196/96 of the Brazilian National Health Council on research involving human beings, and the ethical standards of the International Journal of Sports Medicine (Harriss and Atkinson, 2015).

\section{PARTICIPANTS}

Recruitment of the participants was through publicity in posters and pamphlets in the university community and central region of the city. Participants who were interested in participating of the study were instructed to contact in-person, by phone or e-mail the responsible researcher of this study.

The following inclusion criteria adopted for the present investigation were: (1) to practice running in an advanced way for at least six months prior to the beginning of the study with a minimum frequency of two times a week; (2) present no musculoskeletal dysfunctions that could prevent performance of the tests to be applied; (3) not be taking any medicament or drugs that affect hydration.

Thirty-five individuals were interested in participating in the study, but according to inclusion criteria only 14 men ( $25.2 \pm 6.5$ years) were considered for participation. After receiving information about the purpose of the study and the procedures to which they would be submitted, all participants signed a written informed consent. Participants received instructions outlining guidelines advising them to refrain from any physical exercise (except for the proposed running sessions) and to avoid alcohol, caffeinated beverages, and related diuretics during the study period (from the first to the last visit to the laboratory). Moreover, participants were instructed to maintain their eating habits.

\section{STUDY DESIGN}

The participants made three visits to the laboratory, with a minimum of $72 \mathrm{~h}$ and a maximum of $120 \mathrm{~h}$ between sessions. Visit 1 was directed to study explanation and distribution of a heart rate (HR) monitor to participants for assessing resting HR. Using a crossover scheme, participants were randomly separated for two 60-min running sessions on a treadmill in two different conditions, one with a normal $\mathrm{RH}(53 \pm 1 \%)$ and other with a very high $\mathrm{RH}$ 
(94 $\pm 2 \%)$ (Figure 1). Randomization was done via a computer program (random.org). Anthropometry measurements, $H R$, ratings of perceived exertion (RPE), and urine collection were performed throughout the run (Figure 2). Running in both visits was performed on treadmill (Movement, LX-160, São Paulo, Brazil), without inclination.

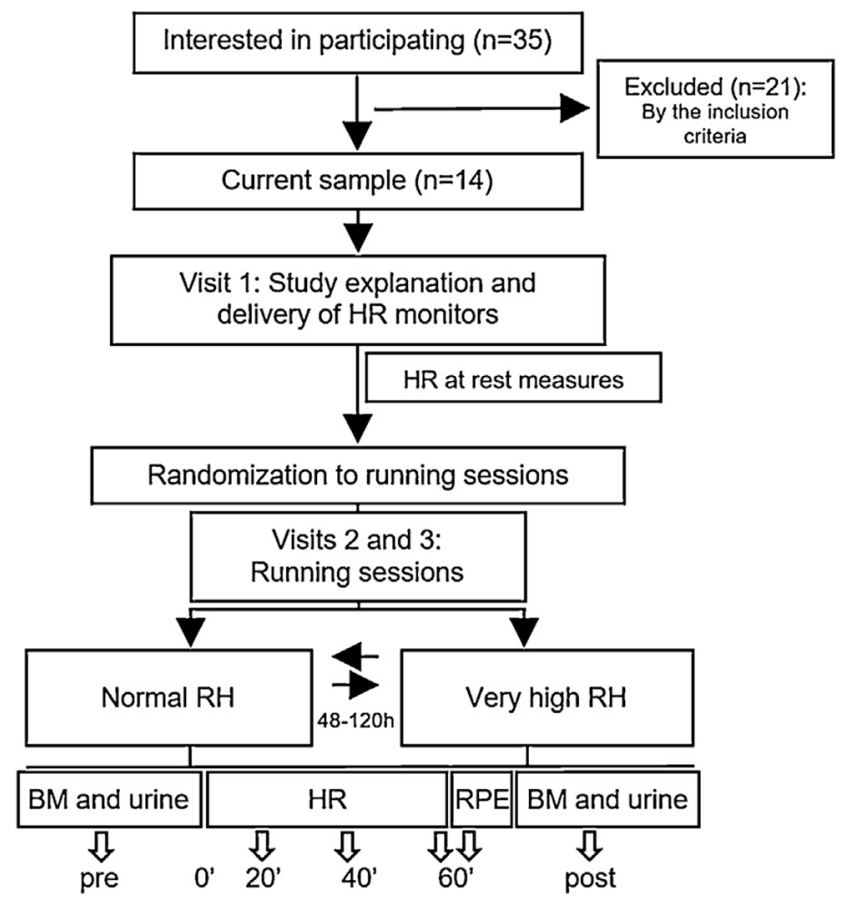

Figure 1. Schematic representation of sample selection and study design.

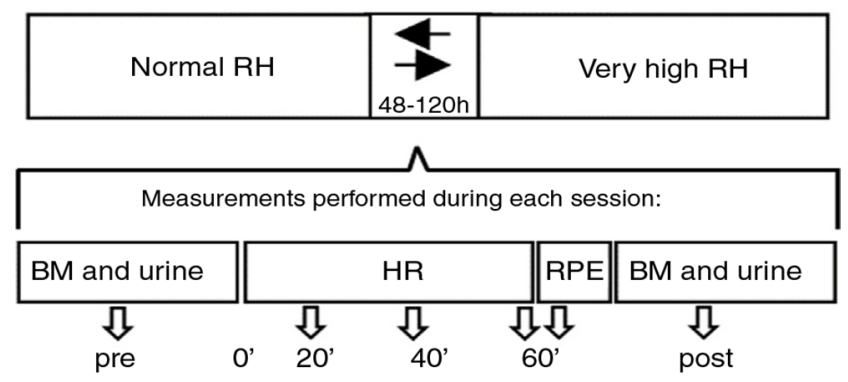

Figure 2. Schematic representation of the experimental sessions (visits 2 and 3 ).

\section{Anthropometry and body composition}

At visit 2, anthropometric measures and body composition were performed. Body mass was measured to the nearest $0.1 \mathrm{~kg}$ using a calibrated electronic scale (Welmy', model W300, São Paulo, Brazil), and height was measured to the nearest $0.1 \mathrm{~cm}$ with a stadiometer attached on the scale. Participants wore light clothes and no shoes. Body mass index was calculated as body mass in kilograms divided by the square of height in meters (WHO 1998). A single-frequency bioelectrical impedance device
(Biodynamic Body Composition Analyzer, model 310e, Biodynamics Corporation, Seattle, USA) was used to determine relative body fat (\%), fat mass $(\mathrm{kg})$, and fat-free mass $(\mathrm{kg})$, according to the manufacturer's proprietary equation. In addition to the initial advice on abstention, participants were also instructed to empty their bladder immediately before the bioimpedance measurement.

\section{Sweating rate}

The SR was estimated by considering the loss of body mass over the course of the running session (Harvey et al., 2008). Body mass was measured 10 min before (body mass pre) and immediately after (body mass post) the participants performed the sessions. SR was estimated by the following equation: $S R=(([$ body mass pre - body mass post $] * 1000) /$ total time session) (Sawka et al., 2007) and expressed in $\mathrm{mL} / \mathrm{min}$.

\section{Hydration status (urine color)}

As a parameter for measuring $\mathrm{HS}$ at each of the visits (2 and 3 ), participants provided a urine sample in transparent plastic bottles $(\sim 40 \mathrm{~mL})$ before and immediately after the tests. The urine color was analyzed using a previously proposed scale (Armstrong et al., 1994; Sawka et al., 2007). This scale evaluates eight different urine colors, ranging from very light yellow (color 1 ) and brownish green (color 8) to define a urine color index to assess HS.

Approximately 60-90 min before the sessions (prior to measurement of body weight), all participants consumed $500 \mathrm{~mL}$ of water in an attempt to standardize/equalize their initial HS. Participants were not allowed to ingest any type of liquid during treadmill running. The higher the HS value on the scale, the greater the dehydration.

\section{Exercise intensity}

In order to determine the intensity to be used in the two running sessions, each participant received a HR monitor (Reebok ${ }^{\circledR}$, model RS1, Finland) at visit 1. They were instructed how to measure the HR using the monitor. To determine resting $\mathrm{HR}$, each participant was to wear the monitor immediately after waking up without standing and record the HR values after one minute of complete rest in supine position. The mean of obtained values of the three days (between visits 1 and 2) was used to characterize the resting HRrest.

Maximum was estimated using the equation proposed in the literature $\left(220-\right.$ age $\left.{ }_{\text {[in years] }}\right)$. The target HR for both running sessions was estimated to be $70-80 \%$ using the HR reserve (HRres) method 
(HRexercise $=$ HRres $\times 0.7$ and $0.8+$ HRrest $)(A C S M, 2011)$. $H R$ was continuously measured throughout the running sessions and recorded at 20, 40, and $60 \mathrm{~min}$. Exercise intensity was maintained at a HR within the HRres range by manipulating treadmill velocity.

RPE was utilized as indicator of stress/physical effort through the application of the modified 11-points scale presented by Borg (1982). The scale, containing verbal and illustrative indications of effort, was presented to participants to assign a numerical value (0-10) corresponding to their overall perception of effort after each session, with 0 being referred as "extremely easy"and 10 as "extremely difficult". RPE was assessed in the last minute of each session.

\section{Environmental conditions for sessions}

Adigital hygrometer (Instrutherm, modelHD-260, São Paulo, Brazil) and an air conditioner (Split Consul, 12000 BTUs, Whirlpool Latin America, Amazonas, Brazil) were used to determine and control the ambient temperature in each test session. The ambient temperature was 22.0 $\pm 0.7{ }^{\circ} \mathrm{C}$. The $\mathrm{RH}$ control was performed using three humidifiers, one from WaterClear-Max (model Turbo Ultrasonic, São Paulo, Brazil) and two from Ventisol (model U-01, Santa Catarina, Brazil). Normal $\mathrm{RH}$ was maintained at $55.9 \pm 5.3 \%$ and very high $\mathrm{RH}$ with maintained at $93.1 \pm 2.3 \%$.

\section{Statistical analysis}

Normality of data was analyzed by the Shapiro-Wilk test. Paired $t$-tests were used to compare SR, distance, $\mathrm{RPE}$, and average speed between RH conditions. Twoway repeated-measures analysis of variance (ANOVA) was used to compare body mass and HS at pre and post sessions between $\mathrm{RH}$ conditions. Fisher's post hoc test was employed to identify the mean differences when $F$-ratio was significant. For all statistical analyses, significance was accepted at $P<0.05$. The data were analyzed using STATISTICA software version 10.0 (Statsoft Inc., Tulsa, OK, USA). Data are presented as mean and standard deviation.

\section{RESULTS}

Table 1 depicts physical characteristic of the participants of the study. The results of Table 2 show the exercise conditions and their respective responses pre-post testing. Running speed, RPE and distance were not different between humidity conditions $(P>0.05)$. Body mass presented a main effect of time (Table 2), with reductions of $1.35 \%$, and $1.65 \%$ for normal and very high $\mathrm{RH}$, respectively. HS was also reduced significantly with no differences between humidity conditions (normal RH: reduction of $14.8 \%$; very high $\mathrm{RH}$ : reduction of $20.8 \%$ ). For the $\mathrm{SR}$, there was a significant difference between $\mathrm{RH}$ conditions, with greater SR for very high RH (+15\%) compared to normal RH condition.

Table 1. Participants' physical characteristics $(n=14)$.

\begin{tabular}{lc}
\hline Variables & Mean \pm standard deviation \\
\hline Age (years) & $25.2 \pm 6.6$ \\
Body mass $(\mathrm{kg})$ & $67.5 \pm 10.6$ \\
Height $(\mathrm{cm})$ & $168.0 \pm 9.5$ \\
Body mass index $\left(\mathrm{kg} / \mathrm{m}^{2}\right)$ & $23.8 \pm 3.0$ \\
Relative body fat $(\%)$ & $18.6 \pm 6.5$ \\
Fat mass $(\mathrm{kg})$ & $12.5 \pm 5.4$ \\
Fat-free mass $(\mathrm{kg})$ & $55.0 \pm 8.3$ \\
\hline
\end{tabular}

The HR measured at the three points during the tests presented a main effect of time $(F=28.49, P<0.05)$ but not an interaction effect $(F=0.17, P=0.83)$, showing similar progressive increases in both conditions. The $\mathrm{HR}$ obtained in very high $\mathrm{RH}$ was significantly elevated by $5.8 \%$ from 20 to $40 \mathrm{~min}, 3.1 \%$ from 40 to $60 \mathrm{~min}$. In normal RH, it increased by $3 \%$ from 20 to $40 \mathrm{~min}$ and $2.3 \%$ from 40 to $60 \mathrm{~min}$ (Figure 3). Similarly, \%HR presented a main effect of time $(F=3.77, P<0.05)$ but not for an interaction effect $(F=0.25, P=0.62)$.

\section{DISCUSSION}

The main findings of the present study were that running under very high $\mathrm{RH}$ or normal $\mathrm{RH}$ at the same environmental temperature causes similar effects on body mass, RPE, HS, and HR. However, a very high RH condition causes greater dehydration (represented by SR) in adult men. Thus, our results partly confirm our previous hypothesis that greater $\mathrm{RH}$ condition produce greater negative physiological alterations in runners.

The body has several ways to transfer heat externally in an attempt to avoid hyperthermia. Among these cooling mechanisms, about $98 \%$ of the effect is through evaporation of sweat (Armstrong and Maresh, 1993; Coris et al., 2004). Attempts at heat dissipated by increased sweating causes reductions in blood circulatory volume and cardiac output and increases in vascular resistance and plasma osmolality (Logan-Sprenger et al., 2012) which result in significant increases in core temperature (Nadel et al., 1977; Murray, 1996; Coris et al., 2004). Additionally, HR will increase approximately 3-5 bpm for every $1 \%$ of body mass loss due to dehydration (Mack et al., 1988). Moreover, a very high $\mathrm{RH}$ will make it difficult to evaporate the sweat, which would prevent heat dissipation by perspiration, further increasing body temperature and 
Table 2. Exercise conditions and respective responses pre and post testing $(n=14)$.

\begin{tabular}{lccccc}
\hline & \multicolumn{2}{c}{ Condition } & \multicolumn{3}{c}{$p$-value } \\
\cline { 2 - 6 } & Normal RH & Very high RH & Condition & Time & Interaction \\
\hline Running speed $(\mathrm{km} / \mathrm{h})$ & $8.7 \pm 0.9$ & $8.8 \pm 0.9$ & 0.109 & - & - \\
Distance $(\mathrm{km})$ & $8.3 \pm 0.9$ & $8.3 \pm 0.8$ & 0.552 & - & - \\
Physical effort (RPE) & $6.4 \pm 1.3$ & $5.4 \pm 1.7$ & 0.07 & - & - \\
Sweating rate (mL/min) & $15.7 \pm 4.9$ & $18.0 \pm 4.4^{\mathrm{b}}$ & 0.028 & - & - \\
Body mass $(\mathrm{kg})$ & & & & 0.619 \\
$\quad$ Pre & $67.4 \pm 10.6$ & $67.6 \pm 11.1$ & 0.955 & $<0.0001$ & \\
$\quad$ Post & $66.5 \pm 10.4^{\mathrm{a}}$ & $66.5 \pm 10.9^{\mathrm{a}}$ & & & \\
Hydration status & & & & & \\
$\quad$ Pre & $3.3 \pm 1.1$ & $3.3 \pm 0.9$ & 0.436 & $<0.0001$ & \\
$\quad$ Post & $3.9 \pm 1.0^{\mathrm{a}}$ & $4.1 \pm 0.9^{\mathrm{a}}$ & & & \\
\hline
\end{tabular}

Note: $\mathrm{RH}$, relative humidity; RPE, rating of perceived exertion. ${ }^{\mathrm{a}} \mathrm{P}<0.05$ vs. Pre. ${ }^{\mathrm{b}} \mathrm{P}<0.05$ vs. Normal RH.
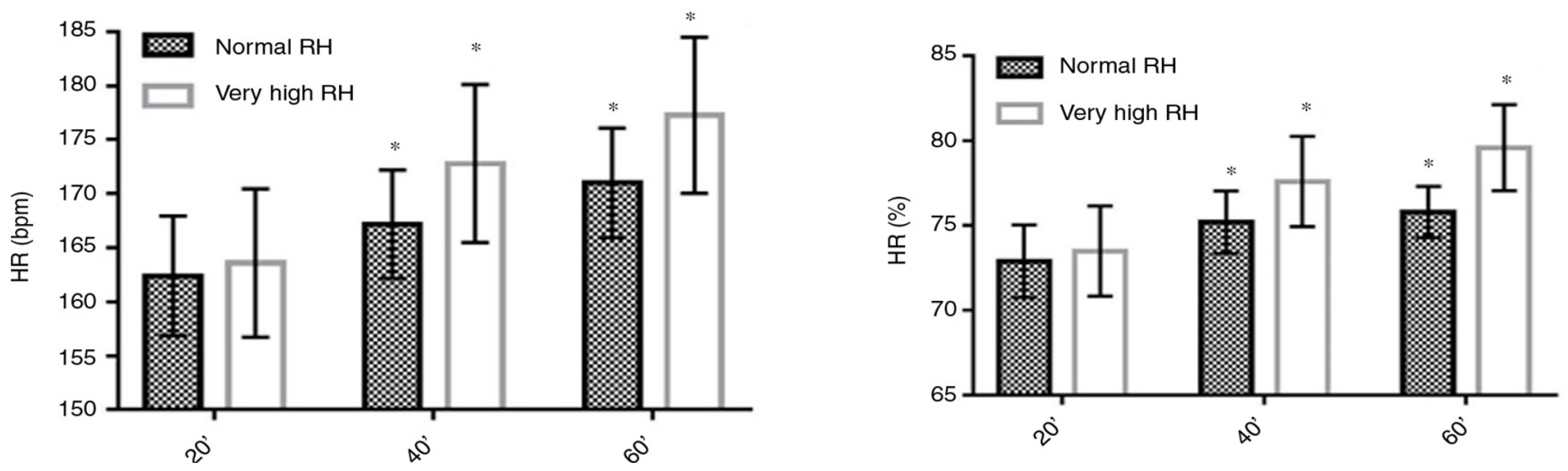

Figure 3. Participants' values of heart rate in both running sessions $(n=14)$. Note. Data are presented as mean and standard deviation for HR. $\mathrm{RH}$, relative humidity; $\mathrm{HR}$, heart rate; *P $<0.05$ vs. 20 '.

overloading metabolism and impairing performance (Wendt et al., 2007). Thus, the increase of SR observed in this study may have occurred due to the body's altered thermoregulation mechanism (i.e., decreased sweat evaporation) and an increase in core temperature (Nadel et al., 1977; Armstrong et al., 1994; Gleeson, 1998).

However, studies involving the analysis of the specific influence of variations in $\mathrm{RH}$ on performance and physiological responses to exercise are scarce. Maughan et al. (2012) analyzed the influence of RH on endurance performance in heat $\left(30.2 \pm 0.2{ }^{\circ} \mathrm{C}\right)$. Eight men participated in four trials to voluntary fatigue at an intensity equivalent to $70 \%$ of maximal oxygen uptake in four different RH conditions: 24,40 , 60 and $80 \%$. SR was significantly higher in the two conditions of higher RH (60 and $80 \%$ ), corroborating the results of the present study. Recently, the changes in game profiles of soccer players under the simultaneous influence of different combinations of ambient temperature and $\mathrm{RH}$ that characterized the games of the FIFA World Cup 2014 were evaluated.
The indicators evaluated included total distance covered and number of sprints performed under the consideration of three air temperature ranges (i.e., below $22{ }^{\circ} \mathrm{C}, 22-28{ }^{\circ} \mathrm{C}$ and above $28{ }^{\circ} \mathrm{C}$ ) and two levels of RH (i.e., below $60 \%$ and above $60 \%$ ). The results showed that the longest total distances occurred at air temperature below $22{ }^{\circ} \mathrm{C}$ and $\mathrm{RH}$ below $60 \%$, while the worst results were in the same temperature range but with $\mathrm{RH}$ conditions above $60 \%$. As for the number of sprint, in games where the temperature was below $22{ }^{\circ} \mathrm{C}$, players performed approximately $30 \%$ more sprints compared to games with temperatures above $28{ }^{\circ} \mathrm{C}$, but this was only observed when the RH was less than $60 \%$ (Chmura et al., 2017). These results indicate that $\mathrm{RH}$ influences performance negatively even when environmental temperatures are similar.

Although our results did not show differences of HR between very high RH and normal RH sessions, Hayes et al. (2014) observed significant increases in $\mathrm{HR}$ and RPE, as well as reductions in power, in athletes 
that performed 40 min of intermittent sprint on cycle ergometer in a high $\mathrm{RH}$ condition $\left(34^{\circ} \mathrm{C}, 78 \%\right)$, compared with normal $\mathrm{RH}$ condition $\left(21^{\circ} \mathrm{C}, 49 \%\right)$. Thus, it may be an interaction effect between temperature and humidity that causes HR to increase when both conditions are high.

For the determination of heat stress and general effort, RPE can be used as a general assessment of effort since it attempts to integrate physiological (type, intensity, and duration of the exercise) and psychological evaluations (feeling of difficulty) (Borg, 1970, 1982). Several investigations have shown that subjects with lower HS usually exhibit higher RPE (Logan-Sprenger et al., 2012; Périard et al., 2012; Hayes et al., 2014; Davis et al., 2015). However, in our investigation, there was no difference in RPE between $\mathrm{RH}$ conditions, which may have been because our results on HS were not different between humidity conditions. The initial urine color values in the present study were similar between the two conditions of $\mathrm{RH}$; after both conditions, HS decreased with the magnitude of this dehydration being slightly greater but not significant $(P>0.05)$ for the very high RH.

Regardless of the results, some limitations need to be addressed. First, the lack of measurement of core body temperature did not allow us to gauge the change in the internal environment during exercise. Another important limitation was the lack of verification of blood and urine biochemical markers, a fact that would allow greater inferences on fluid loss induced by high RH associated with exercise, and its effects on metabolism. The small sample size may limit inferences to larger groups in different sports.

According to ours results, we conclude that running sessions in differing $\mathrm{RH}$ conditions may alter HS, body mass, SR, HR, and RPE in young men. The longer the effort, the greater may be the changes in these parameters suggesting a greater physiological impact of high $\mathrm{RH}$ despite similar environmental temperatures.

\section{CONFLICTS OF INTEREST}

The authors declare no conflicts of interest.

\section{ACKNOWLEDGEMENTS}

The study has not received any funding. The authors thank the subjects for their participation in the study.

\section{REFERENCES}

ACSM. American College of Sports Medicine position stand. Quantity and quality of exercise for developing and maintaining cardiorespiratory, musculoskeletal, and neuromotor fitness in apparently healthy adults: guidance for prescribing exercise. Med Sci Sports Exerc 2011;43:1334-59.
Armstrong LE, Maresh CM. The exertional heat illnesses: a risk of athletic participation. Med Exerc Nutr Heal 1993;2:125$-34$.

Armstrong LE, Maresh CM, Castellani JW, Bergeron MF, Kenefick $\mathrm{RW}, \mathrm{LaGasse} \mathrm{KE}$, et al. Urinary indices of hydration status. Int J Sport Nutr 1994;4:265-79.

Borg G. Perceived exertion as an indicator of somatic stress. Scand J Rehabil Med 1970;2:91-8.

Borg GAV. Psychophysical bases of percieved exertion. Med Sci Sport Exerc 1982;14:377-81.

Chmura P, Konefał M, Andrzejewski M, Kosowski J, Rokita A, Chmura J. Physical activity profile of 2014 FIFA World Cup players, with regard to different ranges of air temperature and relative humidity. Int J Biometeorol 2017;61:677-84.

Coris EE, Ramirez AM, Van Durme DJ. Heat illness in athletes: the dangerous combination of heat, humidity and exercise. Sports Med 2004;34:9-16.

Davis JK, Laurent CM, Allen KE, Green JM, Stolworthy NI, Welch $\mathrm{TR}$, et al. Influence of dehydration on intermittent sprint performance. J Strength Cond Res 2015;29:2586-93.

Gleeson M. Temperature regulation during exercise. Int J Sports Med 1998;19(Suppl. 2):S96-9.

Goulet EDB, Rousseau SF, Lamboley CRH, Plante GE, Dionne IJ. Pre-exercise hyperhydration delays dehydration and improves endurance capacity during $2 \mathrm{~h}$ of cycling in a temperate climate. J Physiol Anthropol 2008;27:263-71.

Harvey G, Meir R, Brooks L, Holloway K. The use of body mass changes as a practical measure of dehydration in team sports. J Sci Med Sport 2008;11:600-3.

Hayes M, Castle PC, Ross EZ, Maxwell NS. The influence of hot humid and hot dry environments on intermittentsprint exercise performance. Int J Sports Physiol Perform 2014;9:387-96.

Logan-Sprenger HM, Heigenhauser GJF, Killian KJ, Spriet LL. Effects of dehydration during cycling on skeletal muscle metabolism in females. Med Sci Sports Exerc 2012;44:1949$-57$.

Mack G, Nose H, Nadel ER. Role of cardiopulmonary baroreflexes during dynamic exercise. J Appl Physiol 1988;65:1827-32.

Maughan RJ, Otani H, Watson P. Influence of relative humidity on prolonged exercise capacity in a warm environment. Eur J Appl Physiol 2012;112:2313-21.

Maughan RJ, Shirreffs SM, Watson P. Exercise, heat, hydration and the brain. J Am Coll Nutr 2007;26, 604S-612S.

Millard-Stafford ML, Cureton KJ, Wingo JE, Trilk J, Warren GL, Buyckx M. Hydration during exercise in warm, humid conditions: effect of a caffeinated sports drink. Int J Sport Nutr Exerc Metab 2007;17:163-77.

Morris DM, Huot JR, Jetton AM, Collier SR, Utter AC. Acute sodium ingestion before exercise increases voluntary water consumption resulting in preexercise hyperhydration and improvement in exercise performance in the heat. Int $J$ Sport Nutr Exerc Metab 2015;25:456-62.

Murray B. Hydration and physical performance. J Am Coll Nutr 2007;26, 542S-548S.

Murray R. Dehydration, hyperthermia, and athletes: science and practice. J Athl Train 1996;31:248-52.

Nadel ER, Wenger CB, Roberts MF, Stolwijk JAJ, Cafarelli E. Physiological defenses against hyperthermia of exercise. Ann N Y Acad Sci 1977;301:98-109. 
Périard JD, Caillaud C, Thompson MW. The role of aerobic fitness and exercise intensity on endurance performance in uncompensable heat stress conditions. Eur J Appl Physiol 2012;112: 1989-99.

Sawka MN, Burke LM, Eichner ER, Maughan RJ, Montain SJ, Stachenfeld NS. Exercise and fluid replacement. Med Sci Sports Exerc 2007;39:377-90.
Shirreffs SM, Jéquier E, Rosenberg I, Sawka M, Dal Canton A, Manz $F$, et al. The importance of good hydration for work and exercise performance. Nutr Rev 2005.

Wendt D, Van Loon LJC, Van Marken Lichtenbelt WD. Thermoregulation during exercise in the heat: strategies for maintaining health and performance. Sports Med 2007;37: 669-82. 